\title{
Influence of Optimal Tooth Modifications on Dynamic Characteristics of a Vehicle Gearbox
}

\author{
Najeeb Ullah*, T. Cong, B. Huan and H. Yucheng \\ The State Key Laboratory of Mechanical Transmissions, Chongqing University, \\ Chongqing 400030, China \\ *Email: najeeb.rr@gmail.com \\ Phone: +8613271956049
}

\begin{abstract}
Considering the practical problems of gear noise and vibration, this work focuses on the gearbox of the electric vehicle as the research object to analyse the impact of gear microtooth modification. First of all, the effort centres itself on minimising the contact stress and making the load distribution better by implementing the tooth modification on both upper and central speed phases. The procedural analysis of gear tooth modification is executed to make the contact pattern better, so edge contact has been avoided and the load is distributed over a wide area of the tooth for both upper and central gear sets. The contact pattern is positioned in the centre of teeth and contact stress is lowered by $20 \%$ to 837 MPA. Then, the peak to peak transmission error is decreased under three proposed modification approaches. Also, contact and bending safety factors are improved as a result of tooth modification. Meanwhile, it was noticed by performing dynamic analysis that right bearings of both upper and central phases have a higher radial response for first two orders which is further decreased to an optimum level as a result of micro-tooth modification strategies.
\end{abstract}

Keywords: Micro tooth modification; contact pattern; transmission error; safety factors; radial response.

\section{INTRODUCTION}

In the present gear manufacturing industry, gear vibration restriction plays the key role as a prominent link of the quality control. In the old times, people always aim to improve the gear precision and accuracy as close as possible to the theoretical tooth shape to minimise the gear noise and vibration. Meanwhile, enhancing transmission quality of gears by only relying on improving the gear manufacturing and installation precision will significantly upswing the market price of gear production. Nonetheless, a transmission error can still be engendered by gear tooth deformation as a result of working loaded cycles, and the transmission error and the vibration will rise with the elevation of the load.

There has been a lot of study on reduction techniques to minimise different kinds of gear noise and vibration; however at present, primary NVH problems are gear whine, gear rattle and Clunk. In addition, one of the prominent contributor to gear noise is transmission error [1]. Wang et al. [2] analysed the vibration characteristics of transmission gearbox using a grey bootstrap method to minimise the vibration. Also, it's also important to use the modification parameters based on actual operating condition so that gearbox vibration can be verified at the end. In previous work, a comparison was made between actual and modified model to check the validity of tooth profile 
modification [3]. However, inertia, thermal response and friction were ignored for simplicity. A novel method in [4] studied the mesh misalignment as a result of gear web and gear macro-geometry optimization. Furthermore, the impact of helix and stress angle on mesh misalignment along the line of action was investigated. Previous researchers performed gear micro and macro geometry to decrease transmission error [5].

Moreover, reference design and optimal design was compared for different parameters while the vibration of housing was also minimised. Reference [6] presented a simulation of system excitation for a train gearbox with one helical gear phase and applied three types of gear micro-geometries including involute barrelling, lead crowning and lead slope. A methodology was proposed to optimise the efficiency and lower the noise and vibration level based on gear modification method [7, 8]. Later on, a coupled vibration model of a herringbone gear transmission was analysed by taking into consideration the time-varying mesh stiffness and damping to study the influence of basic gear macro parameters on the vibration noise of a gearbox [9]. There is no doubt that the electric vehicle industry is moving into the era of high speed and torque so the modelling and its analysis under multi-source excitation can't be ignored. Therefore, the subjective sound perception of electric power train under working conditions was proposed [10].

Furthermore, the impact of tooth modification in the presence of tooth localised defect is studied while its influence on vibration amplitude is also covered in this Divandari et al. [11]. The research conducted in [12] investigated the influence of tooth modification on static transmission error and contact stress analysis is implemented in different loading conditions. A novel proposition in [13] for gear noise reduction is presented by analysing the two gearboxes and their optimising micro-geometry. In addition, the dynamic behaviour of different subcomponents is addressed. A proposition method for the tooth modification amount of a wind turbine gearbox has been studied [14]. The methodologies presented in $[15,16]$ are about gear tooth modification, but the resulting safety factors were ignored in these studies. Later on, the impact of meshing gear system on electric vehicle power-train vibration and the noise was focused on [17].

The combination of different tooth modification approaches, simulation methodology and their impact on the dynamic behaviour of the geared coupled system especially, their resulting safety factors and radial dynamic response is very rare in the literature so far. Therefore, this study is based on the development of a combination of tooth modification strategies for a vehicle gearbox, so firstly, a dynamic model of the gear- shaft-bearing system was established. Focusing on transmission error and NVH performance of electric transmission gearbox, gear modification strategies are developed while the impact of gear micro modification on peak-peak transmission error, safety factors and radial dynamic response is investigated which provide a theoretical basis for vibration and noise reduction of the vehicle gearbox.

\section{STATE OF THE ART}

\section{Modelling and Load Cases of Transmission Gearbox System}

Aimed at a specific transmission system, this study mainly analyses the entire gearbox in the design module of professional software MASTA. The chain of the full modelling process is done to establish the coupled model of all gear shafts and then to find the space position of these shafts, followed by a combination of all components such as gears, bearings and housing etc. According to the detailed parameters of gears, shafts, bearings and housing, the dynamic simulation model was built which is shown in figure1. The 
transmission principle of gearbox used in this study can be explained in such a way that it is made of the upper phase, central phase and lower phase. The input power is induced by an electric motor and transferred to input shaft followed by an en route to pinion and wheel of upper speed phase. Then, the power is transited from pinion of central speed phase to the lower phase.

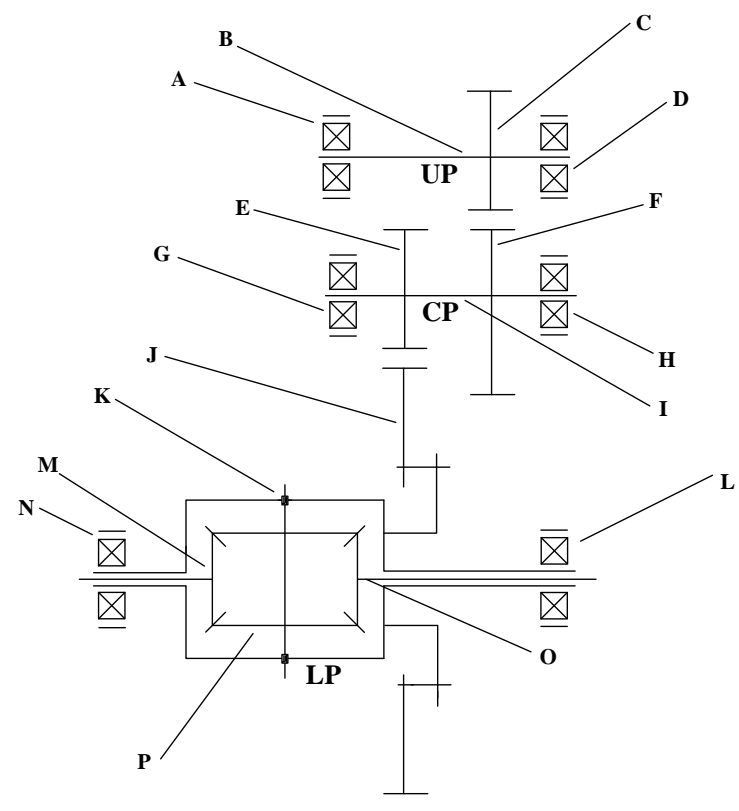

(a) Transmission outline

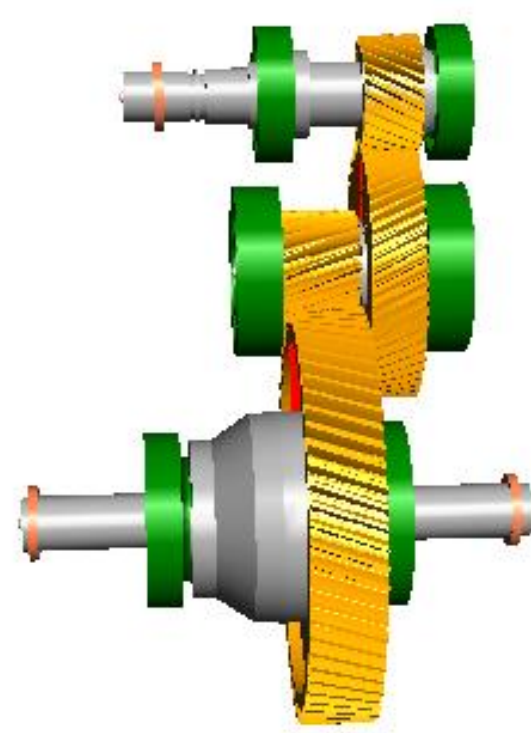

(b) 3D model in MASTA

Figure1. The gearbox transmission system of the electric vehicle.

*(Note: US-Upper phase; CS- Central phase; LS-Lower phase; A,D-bearings of Upper shaft; B-Upper phase shaft; C-Pinion of Upper phase; F-Wheel of Upper phase; I-Central shaft; G,H-bearings of Central shaft; N,L-bearings of lower shaft; O,M-Half axle gear; P-Plant; K-Covering of differential; E-Pinion of central phase; J-Wheel of central phase).

Table1. Structural parameters of the electric vehicle transmission system.

\begin{tabular}{|c|c|c|c|c|c|c|}
\hline \multirow{2}{*}{ Parameter } & \multicolumn{2}{|c|}{ Upper phase } & \multicolumn{2}{|c|}{ Central phase } & \multicolumn{2}{|c|}{ Differential phase } \\
\hline & Pinion & Wheel & Pinion & Wheel & Plant & Sun \\
\hline $\begin{array}{l}\text { Number of } \\
\text { teeth }\end{array}$ & 22 & 58 & 22 & 68 & 12 & 16 \\
\hline Module (mm) & 2.5 & 2.5 & 2.7 & 2.7 & 3.5 & 3.5 \\
\hline $\begin{array}{l}\text { Helix angle } \\
\left({ }^{\circ}\right)\end{array}$ & 22.5 & 22.5 & 18 & 18 & - & - \\
\hline $\begin{array}{l}\text { Pressure angle } \\
\left({ }^{\circ}\right)\end{array}$ & 20 & 20 & 20 & 20 & 22.5 & 22.5 \\
\hline Ratio & \multicolumn{2}{|c|}{2.63} & \multicolumn{2}{|c|}{3.09} & & \\
\hline
\end{tabular}

Since load cases are mainly used to define the actual working conditions of the developed model and these conditions usually refers to loaded torque, rotational speed and actual time under the action of specific power flow. Also, comprehensive dynamic analysis for gear tooth contact need to be conducted across a range of working cycles to 
give detailed information and more precise information [18]. Therefore, the load cases for the running conditions of the proposed gearbox are shown in Table 2.

Table2. Load cases of electric vehicle gearbox.

\begin{tabular}{lcccc}
\hline & Torque $(\mathrm{Nm})$ & Number of cycles & Speed $(\mathrm{rpm})$ & Time $(\mathrm{h})$ \\
\hline & 245 & 9259860 & 4000 & 64 \\
Forward load & 120 & 12363000 & 7500 & 50 \\
& 80 & 73742780 & 12000 & 174 \\
Reverse load & 145 & 6951108 & 4000 & 6 \\
Total & - & - & - & 294 \\
\hline
\end{tabular}

\section{Gear Tooth Micro-Modification Methods}

Gear tooth micro-modification can make the stress uniformly distributed on the tooth contact surface, and it's an effective way to minimise gear transmission error under normal operating conditions. To evaluate the validity of the calculated tooth modification techniques, tooth contact, time-varying and peak-peak transmission error, safety factors and radial response analysis are performed using different modules by a combination of three different modification approaches.

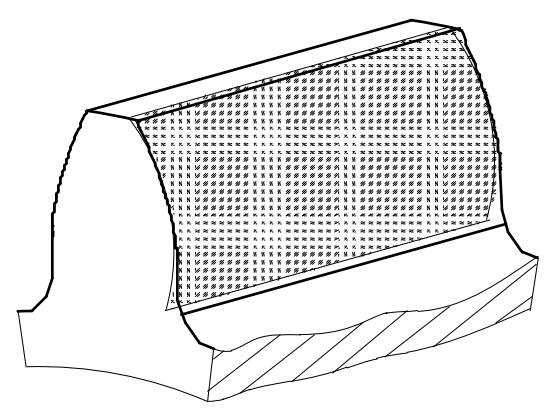

(a) Profile modification

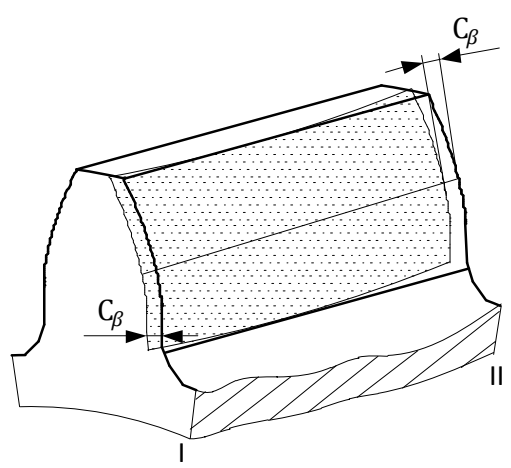

(b) Lead modification

Figure 2. Diagrammatical presentations of profile and tooth modification.

There are also a variety of methods for profile and lead modification. For determining the profile modification parameters mainly, considering the three elements comprising of the maximum amount of modification, modification length, and modification curve are important. In the design stage, it is also critical to determine the maximum amount of modification. Therefore, the following empirical formulae for profile modification based on [19] was used to calculate the maximum amount of modification which is given as follows.

$$
\begin{aligned}
& \mathrm{e}_{\max }=\delta+\delta_{\theta}+\delta_{\mathrm{m}} \\
& \delta=\frac{\mathrm{W}_{\mathrm{t}}}{\mathrm{bC}_{\gamma}} \\
& \delta_{\theta}=\pi \mathrm{m}_{\mathrm{n}} \cos \alpha \Delta_{\theta} \gamma 10^{3}
\end{aligned}
$$


In Eq. (1), $\delta$ is the amount of deformation caused by the load; $\delta_{\theta}$ is the deformation caused by the temperature difference between the two meshing gears; $\delta_{\mathrm{m}}$ is manufacturing deformation error. In Eq. (3) and (4), $\mathrm{W}_{\mathrm{t}}$ is the circumferential force; $\mathrm{C}_{\gamma}$ is the meshing stiffness; $\mathrm{b}$ is the tooth width; while $\Delta_{\theta}$ is the temperature difference of the meshing gear; $\gamma$ is the coefficient of linear expansion of the material while $m_{n}$ is the normal module. The length of modification is calculated by the following formula:

$$
\lambda=\mathrm{P}_{\mathrm{b}}\left(\varepsilon_{\alpha}-1\right)
$$

where $\lambda$ is the length of the modification, $P_{b}$ is the gear base, $\varepsilon_{\alpha}$ is the transverse contact ratio of gear. On the other hand, the tooth lead modification refers to a method of modifying the drum shape of the middle of the tooth width, but the shape of both end sides remains symmetrical. However, the accurate selection of the shape involves more factors and a larger amount of calculation. The following empirical formula for lead modification is used to calculate the amount of crowning relief.

$$
\mathrm{C}_{\beta}=\frac{\mathrm{b}_{\mathrm{cal}} \mathrm{F}_{\beta \mathrm{y}}}{\mathrm{b}}
$$

where $\mathrm{C}_{\beta}$ is the amount of drum modification; $\mathrm{b}_{\mathrm{cal}}$ is the contact width; $\mathrm{F}_{\beta \mathrm{y}}$ is the meshing tooth longitudinal error; $\mathrm{b}$ is the tooth width. The tooth load distribution is greatly affected by the meshing tooth longitudinal error whose calculation formula is as follows.

$$
\mathrm{F}_{\beta \mathrm{y}}=\mathrm{W}_{\mathrm{m}} \mathrm{f}_{\mathrm{sho}}+\mathrm{f}_{\mathrm{p}}-\mathrm{y}_{\mathrm{B}}
$$

where $\mathrm{W}_{\mathrm{m}}$ and $\mathrm{f}_{\text {sho }}$ show the average load per unit tooth width and the actual deformation under unit load respectively; $f_{p}$ is the misalignment error caused by the tooth direction error, the whole position error and the bearing deformation while $\mathrm{y}_{\beta}$ stands for the tooth run direction.

According to the formulae above, the tooth micro modifications parameters were determined by considering forward and reverse load cases as revealed in Table 2. In addition, three tooth micro modification strategies are shown in Table 3 which were performed according to different manual parameters by following Figure 3(a) to (d). Figure 4(a) and (b) shows the actual tooth stress and contact pattern without any modification. Whereas, Figures 4(c) to (h) are the detailed tooth modification curves both in lead and profile direction as a result of implementing first, second and third modification approaches described in Table 3. Besides that, mesh attributes were studied

\begin{tabular}{|c|c|c|}
\hline Methods & Lead Modification & Profile modification \\
\hline 1st strategy & Linear modification & Linear + Barreling modification \\
\hline 2nd strategy & $\begin{array}{l}\text { Crowning +Linear } \\
\text { modification }\end{array}$ & Linear + Barreling modification \\
\hline 3rd strategy & Crowning relief & Barreling modification \\
\hline
\end{tabular}
and calculated.

Table 3. Strategies for tooth modification 


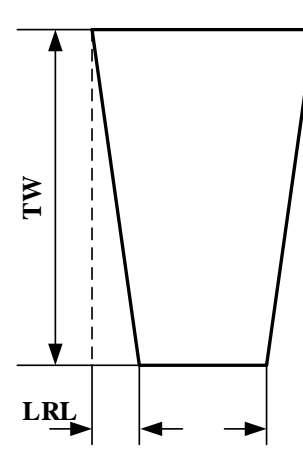

(a) linear relief

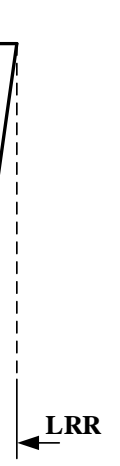

(b) crowning /parabolic relief

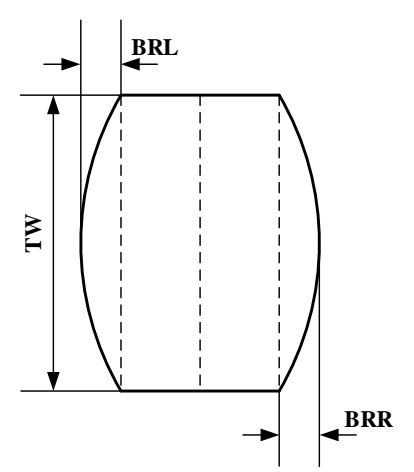

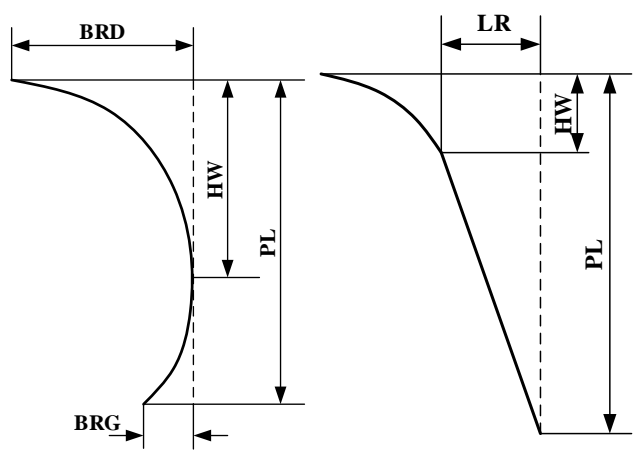

(c) barreling

(d) linear

Figure 3. Basic parameters for (a), (b) lead and; (c), (d) profile modification.

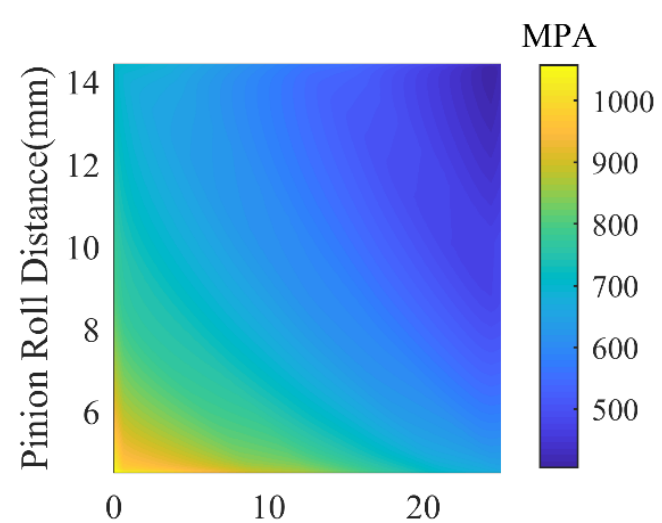

Effective Face Width(mm)

(a) upper phase

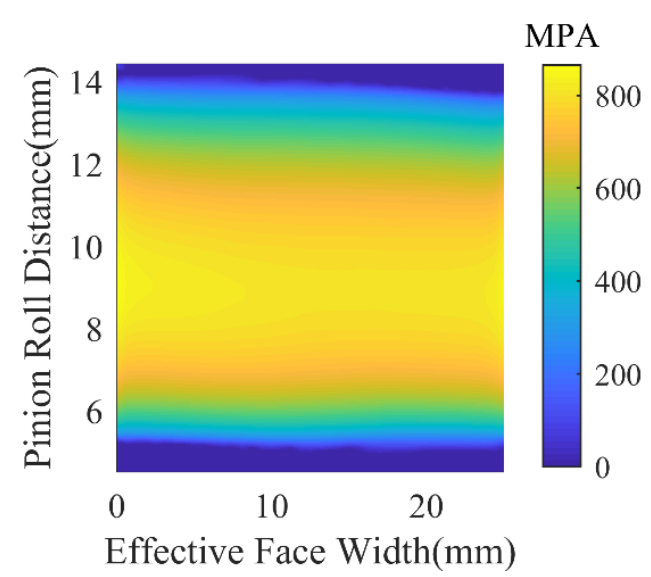

(c) upper phase

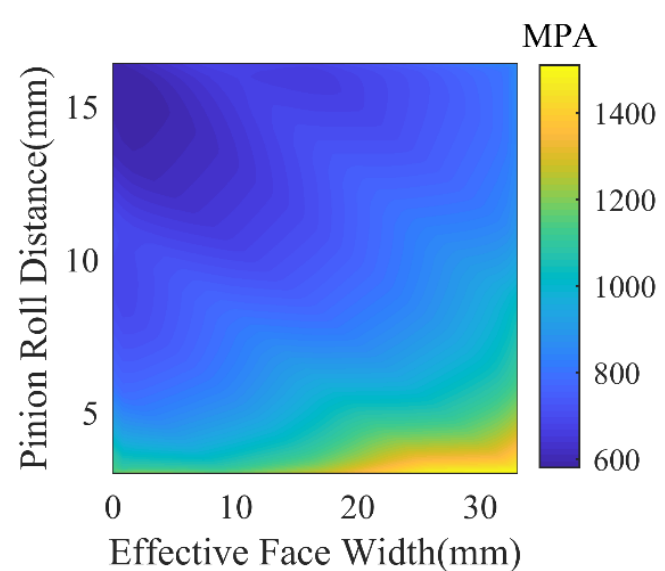

(b) central phase

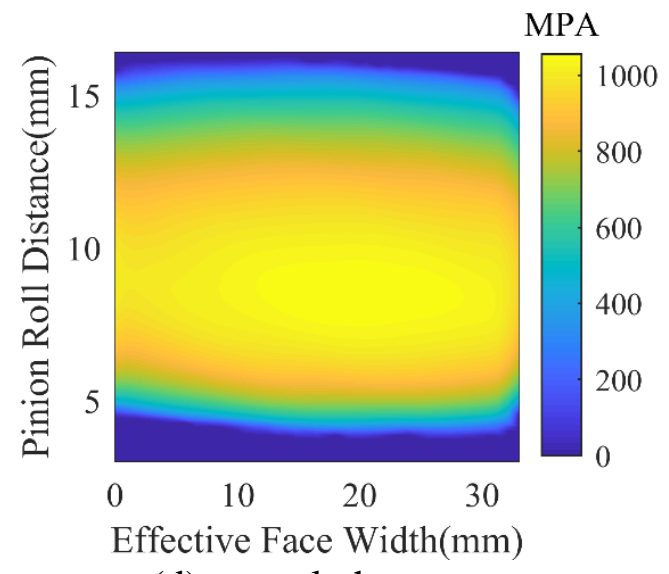

(d) central phase 

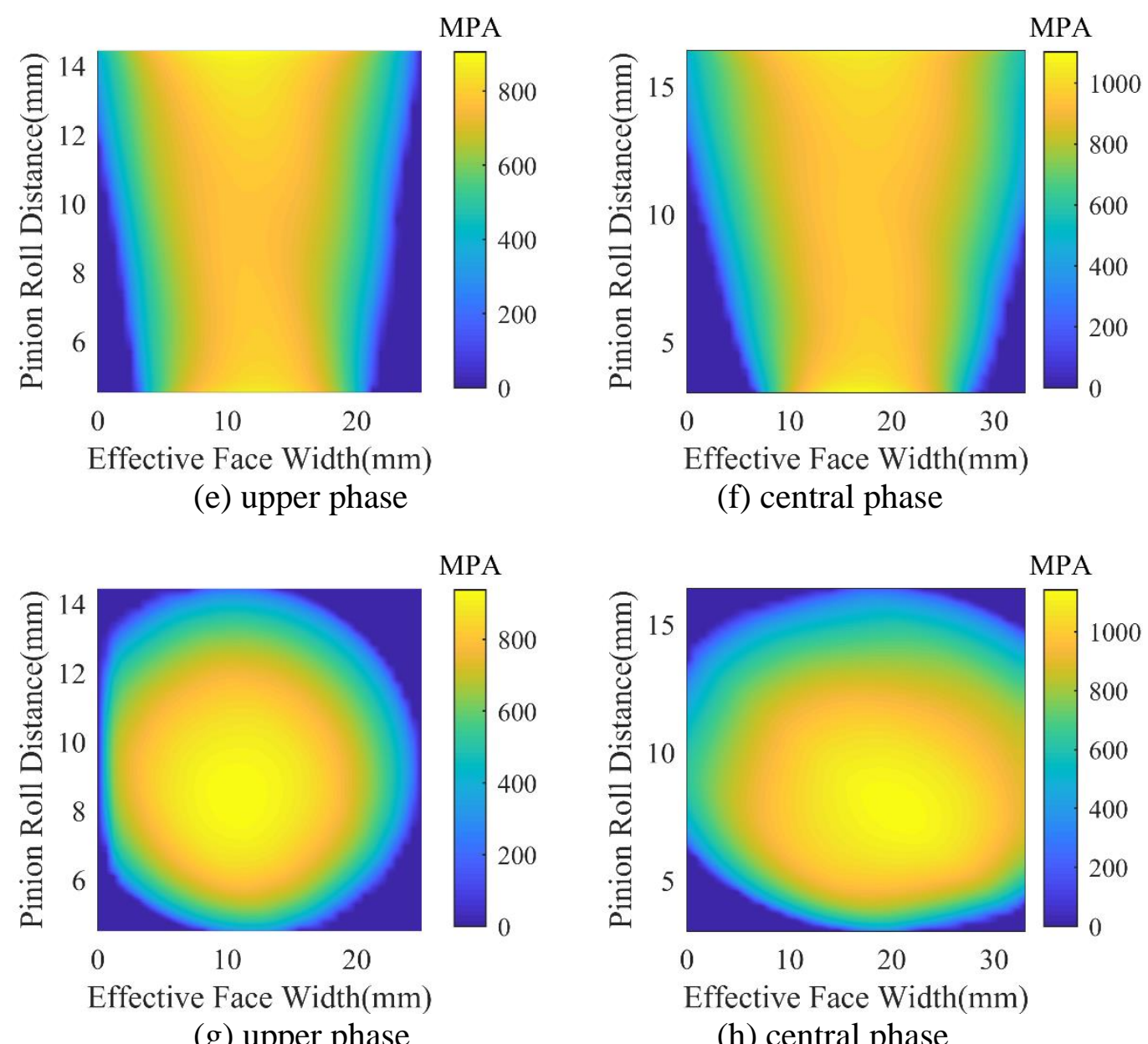

Figure 4. Contact patterns at the upper and central phase for (a), (b) actual approach (without modification), (c), (d) first strategy, (e), (f) second strategy and; (g), (h) third strategy.

The simulated results show that relatively more contact stress, as well as significant edge contact, exist for the actual modules which are without tooth modification in Figure 4 for both upper and central speed phases due to deflection of the shaft during load conditions. More specifically, the contacts of the tooth surface were concentrated on the sides of the teeth, and the contacts were also concentrated on the tooth roots of both upper and central phases. For linear tooth modification, it contains crowning, linear and tooth end modification while linear, barrelling and pressure angle modification comes under the category of profile tooth modification. However, this study considers only the prescribed modifications shown in Figure 3. After modification, the contact pattern, contact stress and the peak-peak transmission error are studied. By looking into details, it is obvious that proposed modification approaches not only enhance the contact pattern but also lowers the topmost values of contact stress. Table 3 shows the combination of different approaches which were manually applied in MASTA to avoid the edge contact. Figure 4 (c) and (d) is for the first approach outcomes which reveal that contact pattern in profile direction display a good stress distribution while tooth width direction unveils a significant edge contact.

Regarding the second approach, significant edge contact can be seen in profile direction in Figure 4 (e) and (f). While coming to the third strategy, it shows much better 
contact stress distribution as opposed to first and second strategy as presented in Figure $4(\mathrm{~g})$ and $(\mathrm{h})$. From Figure $4(\mathrm{~g})$ and $(\mathrm{h})$, it is also apparent that the contact pattern also moved to the middle in both tooth profile and the tooth width direction

\section{DISCUSSION}

\section{Transmission Error Analysis}

Peak to peak values of transmission error including safety factors were explained while the transmission error in a single mesh cycle is shown in Figure 5. Three proposed approaches show minimal values of peak to peak transmission error as compared to the actual scheme which is without tooth micro-modification. A similar trend can be seen for the central phase where the third strategy also minimised the peak transmission error in a relatively better way as compared to first and second approaches. The peak-peak transmission error, contact stress and reduction ratings are presented in Table 4 and 5 respectively. Then, the third tooth modification strategy was eventually used to calculate and analyse the radial response and safety factors of the system.

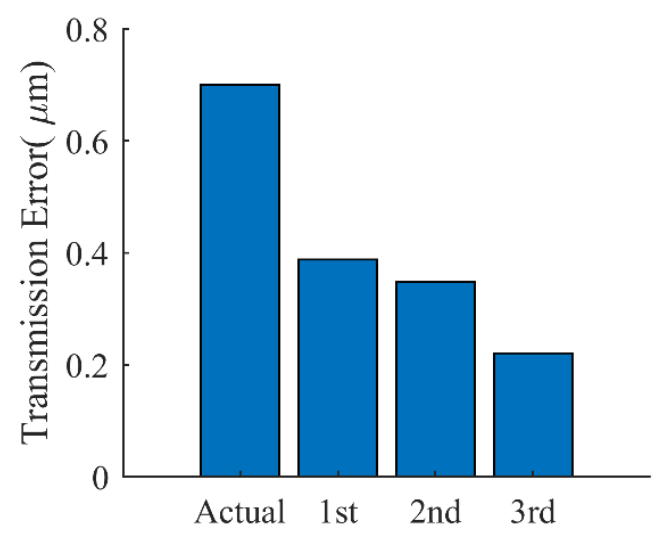

(a) upper phase transmission error

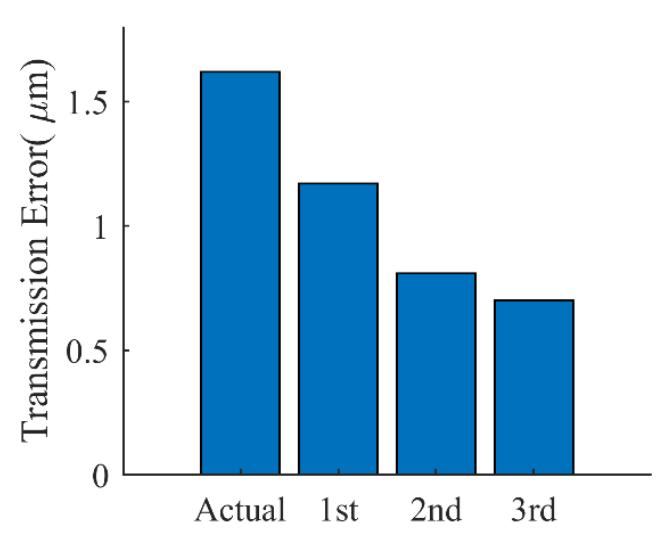

(b) central phase transmission error

Figure 5. Peak to peak transmission error.

Table 4. Peak to peak transmission error and reduction percentage.

\begin{tabular}{lcccc}
\hline Strategy & $\begin{array}{c}\text { Upper phase } \\
(\mu \mathrm{m})\end{array}$ & $\begin{array}{c}\text { Reduction } \\
\text { rating }\end{array}$ & $\begin{array}{c}\text { Central phase } \\
(\mu \mathrm{m})\end{array}$ & $\begin{array}{c}\text { Reduction } \\
\text { rating }\end{array}$ \\
\hline Actual & 0.7 & - & 1.62 & - \\
1st strategy & 0.3878 & $44.60 \%$ & 1.17 & $27.70 \%$ \\
$\begin{array}{l}\text { 2nd } \\
\text { strategy }\end{array}$ & 0.3475 & $50.30 \%$ & 0.8118 & $49.80 \%$ \\
$\begin{array}{l}\text { 3rd } \\
\text { strategy }\end{array}$ & 0.2206 & $68.40 \%$ & 0.7 & $56.70 \%$ \\
\hline
\end{tabular}


Table 5. Contact stress and reduction percentage.

\begin{tabular}{lcccc}
\hline $\begin{array}{l}\text { Contact Stress } \\
(\mathrm{MPa})\end{array}$ & $\begin{array}{c}\text { Upper } \\
\text { phase }\end{array}$ & $\begin{array}{c}\text { Reduction } \\
\text { rating }\end{array}$ & $\begin{array}{c}\text { Central } \\
\text { phase }\end{array}$ & $\begin{array}{c}\text { Reduction } \\
\text { rating }\end{array}$ \\
\hline Actual & 1285 & - & 1511 & - \\
1st strategy & 907 & $29.40 \%$ & 1057 & $30.04 \%$ \\
2nd strategy & 939 & $26.92 \%$ & 1122 & $25.7 \%$ \\
3rd strategy & 867 & $32.5 \%$ & 1104 & $26.9 \%$ \\
\hline
\end{tabular}

\section{Safety Factors Analysis}

The safety factor is defined as the scaling factor that is applied to the load case stress of each load case that gives a total duty cycle damage of $100 \%$. Since safety factors and total compliance of meshing gears can't be ignored while designing any component of machinery so impact of all three strategies on safety are analysed in this section. A basic ISO 6336 rating was carried out by including the effect of misalignment and the safety factors was improved which is presented in Figure 6. The safety factor indicates how far away from the maximum stress the load case result is.

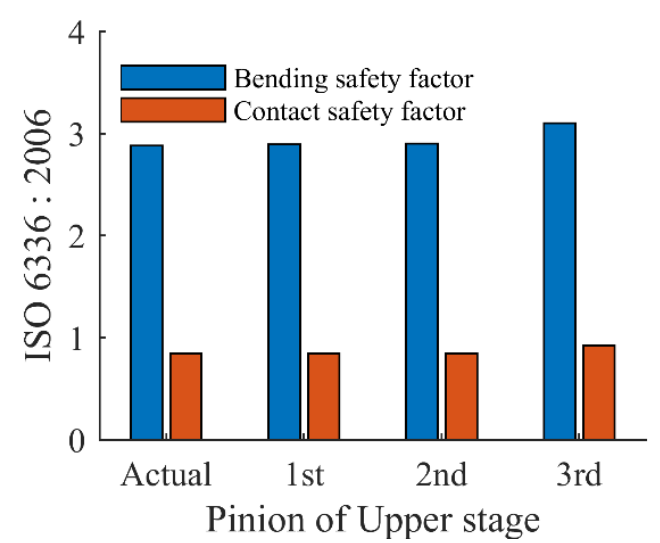

(a) pinion

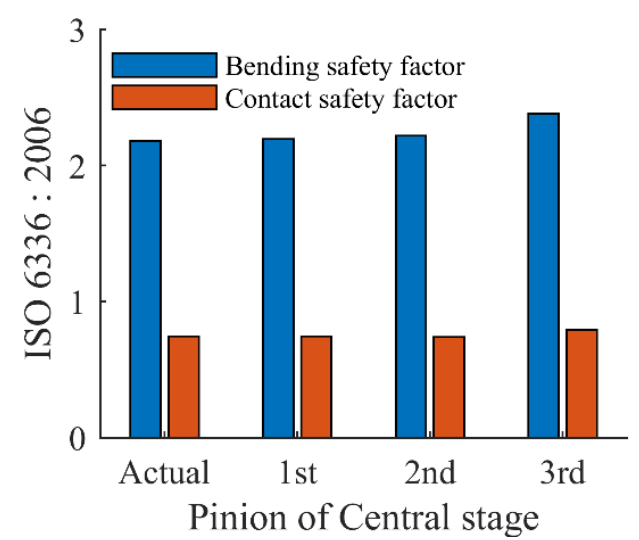

(c) pinion

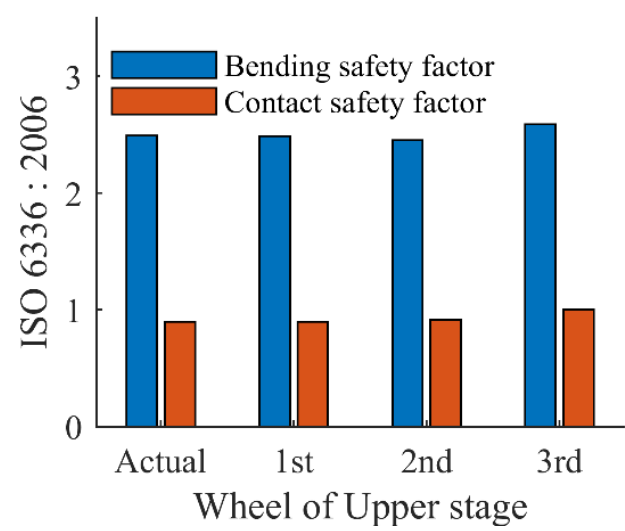

(b) wheel

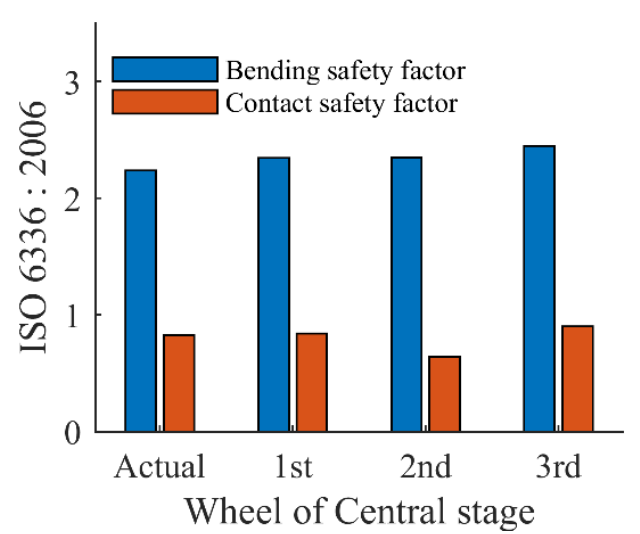

(d) wheel

Figure 6. Safety factors for pinion and wheel at the (a), (b) upper and; (c), (d) central phase. 
For the pinion of the upper phase, contact and bending safety factors for actual, first and second strategy were almost the same while effective improvement can be seen for the third approach for both pinion and wheel. In the same way, the pinion of central speed shaft shows almost similar values of contact and bending safety factors for the first and second strategy. However, topmost values of both safety factors for the third strategy are increased obviously. Overall, the third strategy proved to be more effective in enhancing safety factor values. Coming to the pinion of central speed phase, all the bending safety factors are little less as compared to the pinion of upper phase shaft. In addition, the pinion of the central phase shows that contact and bending safety factors are almost the same for first and second strategy and the third strategy showed better improvement.

In contrast, the wheel of the central phase shows the opposite trend. Contact safety factors for actual and first strategy are the same while there is minimal difference in bending safety factors of the first and second strategy for the wheel of central phase. However, the contact safety factor was decreased for the second strategy and effectively improved under the third approach along with bending safety factor.

\section{Radial Acceleration Response Analysis}

The vehicle gearbox used in this study has a comparatively higher operating speed which lies in the region of almost 7000-12000 rev/min. Therefore, the dynamic response especially radial acceleration can't be ignored due to which even radiation noise originates during working conditions. Hence, the radial acceleration response for first two harmonics is analysed whose mesh frequencies remain up to $5 \mathrm{kHz}$ and $10 \mathrm{kHz}$ for both first and second orders respectively. Radial acceleration response analysis is done for the upper and central speed phase for the actual and most effective third approach. It can be seen in Figure 7 (a) that the first order radial acceleration for the right bearing of the upper phase shaft is high without modification. Whereas, the second order response without modification is comparatively low as compared to the first order radial response. It is also worth mentioning to note that radial acceleration of the third order approach of micromodification declined for both first and second orders.

First order without modification

First order of third strategy

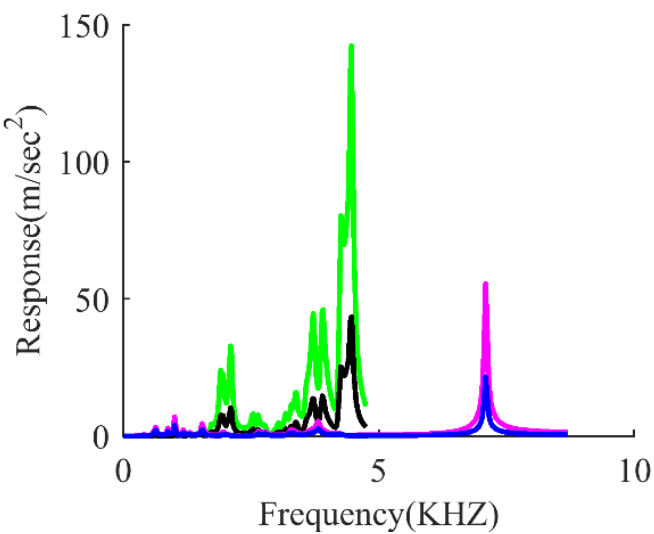

(a) right bearing
Second order without modification Second order of third strategy

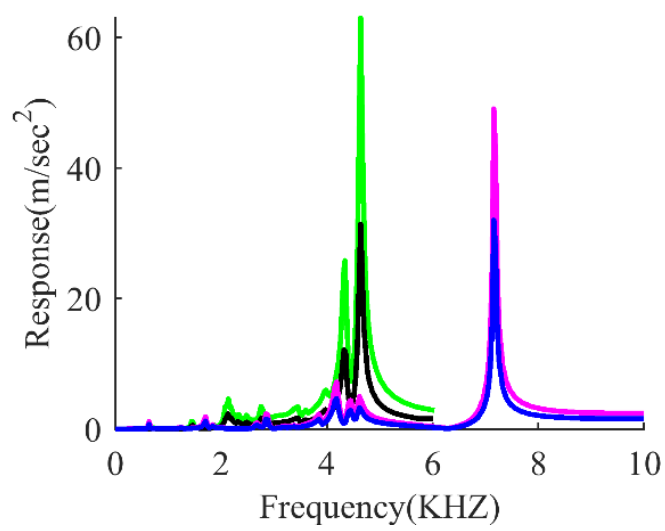

(b) left bearing 


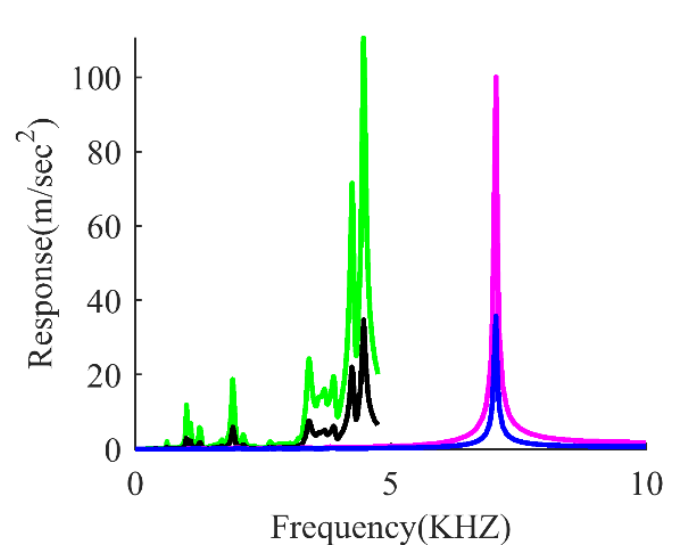

(c) right bearing

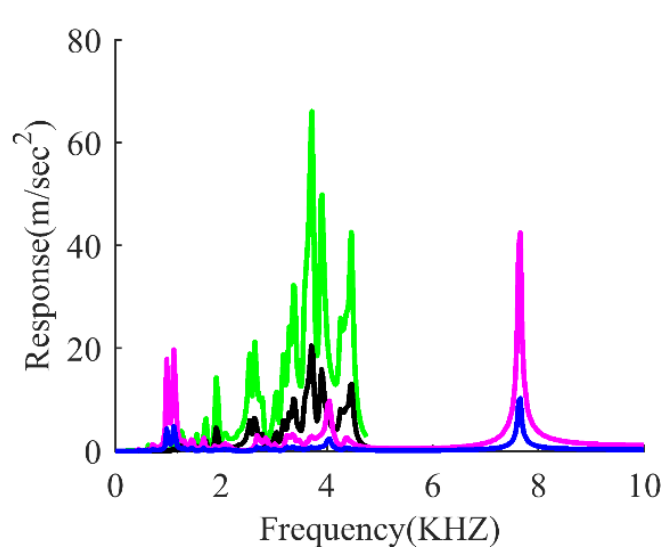

(d) left bearing

Figure 7. Radial acceleration of (a), (b) upper phase and; (c), (d) central phase in the right and left bearing.

By taking a glance at Figure 7(b), it is obvious that first order radial response without modification is still high as compared to the second order response. In contrast, simulation results showed that first-order radial response of right bearing in Figure 7(a) is high as opposed to first order radial response of left bearing for the upper phase. By looking at Figure 7(c), it is noticeable that the right bearing of the middle phase shaft showed a high radial response not only for the first order but also for second-order response. Besides, the left bearing of the central phase shaft presents a comparatively low radial response in Figure 7(d). Again, the third modification approach proved to be an effective technique and lowered the radial response for both the upper and central phase shaft bearings.

\section{CONCLUSION}

The presented modification approaches provided many valuable insights for the vehicle gearbox. This study considered not only the original capabilities of developed strategies but also their limits for gear noise and vibration reduction research. From the prescribed research, dynamic analysis comes off the following conclusions.

i. By following transmission procedural analysis, vehicle gearbox dynamic model was built, and three approaches were implemented to analyse mesh contact behaviour. The third strategic modification which is a combination of crowning and barreling technique proved to be more productive due to which contact pattern is improved, and maximum stress is minimised.

ii. In addition, the impact of different modification approaches on peak-peak transmission error, safety factors and radial acceleration for both phases is investigated. However, the third technique still remains dominant which even as peak-peak transmission error values and therefore, the objective of minimising vibration and noise is also fulfilled since transmission error is reduced as a result of tooth micro-optimisation.

iii. As far as durability of geared systems is concerned, the importance of safety factors can't be ignored, so safety factors are slightly enhanced and compared for all three approaches. In both kinds of safety factors, there is a slight difference in safety factor values for the first and second proposed approach as opposed to 
actual safety factor values. However, the third proposed strategy comparatively boosted safety factors better as opposed to other modification approaches.

iv. Finally, dynamic simulation results showed that both right bearings of upper and central phase shafts have higher order radial response. Meanwhile, the third approach led to diminishing radial response for both pairs of bearings in case of upper and central phase shafts. As a result, optimum first and second order radial acceleration has been gained for all bearings of both phases. The dynamic analysis results especially the third strategy of gear tooth modification and optimisation can be highly recommended for vibration control in applications of engineering design and industrial level.

\section{REFERENCES}

[1] Yue G, Niu W, Zhao J, Kong D, Li Y, Hou H. Gear Whine Resolution by Tooth Modification and Multi-Body Dynamics Analysis. SAE 2016 World Congress and Exhibition: SAE International; 2016. p. 2016-01-1061.

[2] Wang H-l, Deng X-z, Li J-b, Yang J-j. Dynamic assessment of vibration of tooth modification gearbox using grey bootstrap method. Shock and Vibration. $2015 ; 2015$.

[3] Li Z, Mao K. The tooth profile modification in gear manufacture. Applied Mechanics and materials: Trans Tech Publ; 2008. p. 317-21.

[4] Ganti V, Dewangan YK, Subramanian G. Influence of Gear Web and Macro Geometry on Mesh Misalignment. International Mobility Conference: SAE International 2016. p. 2016-28-0082.

[5] Åkerblom M. Gear Geometry for Reduced and Robust Transmission Error and Gearbox Noise. 2008. In Proceedings OST - Symposium on Machine Design, KTH, Stockholm, pp. 18; 2008.

[6] Sathyanarayana P, Kumar GS. Optimization of single speed EV drivetrain for commercial electric vehicles. 2017 IEEE Transportation Electrification Conference (ITEC-India): IEEE; 2017. p. 1-3.

[7] Li YX, Shen WQ, Zhao YJ, Hu XY. Gear Modification Analysis to Improve the Vibration and Noise of Automobile Transmission. Key Engineering Materials: Trans Tech Publ; 2014. p. 265-9.

[8] Guan YH, Lim TC, Shepard WS. Experimental study on active vibration control of a gearbox system. Journal of Sound and Vibration. 2005;282:713-33.

[9] Zhou J-X, Liu G, Wu L-Y. Effect of operating conditions on vibration and noise radiation of a gear reducer. Zhendong yu Chongji(Journal of Vibration and Shock). 2013;32:193-8.

[10] Fang Y, Zhang T. Modeling and analysis of electric powertrain NVH under multisource dynamic excitation. SAE 2014 International Powertrain, Fuels \& Lubricants Meeting: SAE International; 2014. p. 2014-01-870.

[11] Divandari M, Aghdam B, Barzamini R. Tooth profile modification and its effect on spur gear pair vibration in presence of localized tooth defect. Journal of Mechanics. 2012;28:373-81.

[12] Park J, Seo C, Boo K, Kim H. Geometry Modification of Helical Gear for Reduction of Static Transmission Error. MATEC Web of Conferences: EDP Sciences; 2018. p. 02013.

[13] Bihr J, Heider M, Otto M, Stahl K, Kume T, Kato M. Gear noise prediction in automotive transmissions. International Gear Conference2014. p. 457-65. 
[14] Kim J, Park N, Lee H. Tooth modification for optimizing gear contact of a windturbine gearbox. Proceedings of the Institution of Mechanical Engineers, Part C: Journal of Mechanical Engineering Science. 2016;230:1318-30.

[15] Xiang C, Song C, Zhu C, Weng Y, Guo W. Effects of Tooth Modifications on the Mesh and Dynamic Characteristics of Differential Gearbox Used in Electric Vehicle. Iranian Journal of Science and Technology, Transactions of Mechanical Engineering. 2018:1-13.

[16] Ghosh S, Chakraborty G. On optimal tooth profile modification for reduction of vibration and noise in spur gear pairs. Mechanism and Machine Theory. 2016;105:145-63.

[17] Wang P, Yu P, Zhang T. Gear Tooth Modification of EV Powertrain for Vibration and Noise Reduction. WCX World Congress Experience: SAE International; 2018. p. 2018-01-1289.

[18] Harris OJ, Langlois PP, Cooper G. Noise Reduction in an EV Hub Drive Using a Full Test and Simulation Methodology. Gear Technology. 2016.

[19] Xi C. Noise Analysis and Optimization of High Speed Wheel Reducer Used in Electrical Vehicle. China: Chongqing University; 2018. 